\title{
POLÍTICA EXTERNA E DESENVOLVIMENTO ECONÔMICO NO BRASIL: HISTÓRIA E PARADIGMAS (1930 - 2016)
}

\author{
FOREIGN POLICY AND ECONOMIC DEVELOPMENT IN BRAZIL: HISTORY AND \\ PARADIGMS (1930 - 2016)
}

Isaías Albertin de Moraes ${ }^{1}$

\begin{abstract}
Resumo
O presente artigo tem como escopo abordar como que a busca pelo desenvolvimento econômico influenciou na formação dos paradigmas da política externa brasileira. Na primeira seção do trabalho, procurou-se operacionalizar o conceito de política externa e de desenvolvimento econômico. Na segunda seção, a pesquisa almejou expor os paradigmas na política externa brasileira para o desenvolvimento econômico de 1930 a 2016, isto é, o paradigma desenvolvimentista, o paradigma neoliberal e o paradigma logístico. Para tanto, utilizou-se como metodologia a Análise Paradigmática das Relações Internacionais desenvolvida por Amado Cervo e que tem expressiva influência dos estudos econômicos. $O$ resultado encontrado foi que o paradigma logístico procura superar os valores do paradigma neoliberal ao mesmo tempo em que reestrutura o sistema de ideias e percepção de mundo do paradigma desenvolvimentista, podendo, portanto, ser considerado um avanço teórico e cientifico significativo na comunidade e na referência dos estudos desenvolvimentistas.
\end{abstract}

Palavras-Chave: Política Externa Brasileira; Desenvolvimento Econômico; Análise Paradigmática das Relações Internacionais.

\begin{abstract}
The present article aims to understand how the pursuit of economic development influenced the formation of Brazilian foreign policy paradigms. In the first section of the paper, we tried to operationalize the concept of foreign policy and economic development. In the second section, the research aimed at exposing the paradigms in Brazilian foreign policy for economic development from 1930 to 2016, that is, the developmental paradigm, the neoliberal paradigm and the logistic paradigm. For that, the text used as methodology the Paradigms of International Relations developed by Amado Cervo and that has significant influence of economic studies. The result was that the logistic paradigm seeks to surpass the values of the neoliberal paradigm while restructuring the system of ideas and world perception of the developmental paradigm and can be considered a significant theoretical and scientific advance in the community and reference of development studies.
\end{abstract}

Keywords: Brazilian foreign policy; Economic development; Paradigms of International Relations.

\section{INTRODUÇÃO}

O objetivo do artigo é buscar estabelecer uma construção teórico-lógico-argumentativa visando a arquitetar questões significativas para auxiliar na melhor compreensão do

\footnotetext{
1 Pesquisador do Núcleo de Extensão e Pesquisa em Economia Solidária, Criativa e Cidadania (NEPESC/Unesp). Doutorando em Ciências Sociais pela Unesp/Araraquara. Bolsista da Coordenação de Aperfeiçoamento de Pessoal de Nível Superior (CAPES). E-mail: isaias.a.moraes@unesp.br. ORCID: http://orcid.org/0000-0003-1839-803X.
} 
relacionamento entre política externa e desenvolvimento econômico no Brasil no período de 1930 a 2016. A metodologia utilizada é a Análise Paradigmática das Relações Internacionais desenvolvida por Amado Cervo. O propósito do texto, portanto, não abrange avaliar detalhadamente e especificamente cada ação da política externa em cada período, mas concepções e sistema de ideias que estruturam um paradigma por determinado período. As correlações realizadas pelo artigo, dessa maneira, estabelecem um aporte histórico-teórico e não tem a pretensão de serem mensuráveis por variáveis.

Os estudos relacionados à política externa na América Latina apresentam, segundo Amado Cervo (2008), como problema epistemológico central a questão do desenvolvimento econômico. Em relação ao Brasil, Cervo (2008) afirma que o desafio do desenvolvimento econômico vem norteando a formulação da política externa desde 1930.

Segundo Cervo (2008), as ações e a estruturação das diretrizes da política externa em busca de autonomia e de desenvolvimento econômico sofreram influências de significativos pensamentos econômicos ao longo do tempo. O autor identifica quatro paradigmas que orientaram as relações internacionais do Brasil desde sua independência. São eles: liberalconservador (século XIX até 1930); desenvolvimentista (1930 - 1989); e, por último, dois que estão em disputa para tornarem-se dominantes, o neoliberal (1990-2002) e o logístico (20032016).

Na primeira seção do artigo, operacionalizaram-se os conceitos de política externa e de desenvolvimento econômico. Na segunda seção, o estudo expôs os paradigmas na política externa brasileira para o desenvolvimento econômico de 1930 a 2016. A escolha do recorte historiográfico se deve em virtude de que o paradigma liberal-conservador (século XIX até 1930) foi demasiadamente descrito por diversos historiadores, por exemplo Bueno (1995, 2003); Brigagão e Silva (2001); Cervo e Bueno (2002); Ricupero (2017), logo o artigo não inovaria em apresentá-lo e o período de 2016-2019 ainda está construindo um novo paradigma de política externa. A pesquisa optou em priorizar como procedimentos técnicos uma abordagem sistemática por meio da avaliação crítica dos dados bibliográficos e documentais.

\section{POLÍTICA EXTERNA E DESENVOLVIMENTO ECONÔMICO}

O surgimento histórico da política externa está correlacionado diretamente com o próprio nascimento do conceito de Estado-nação. Historicamente, pode-se marcar o surgimento do Estado, com características de uma entidade soberana e acima de qualquer outro poder presente na sociedade, a partir da Paz de Westfália em 1648. Após a Guerra dos Trinta Anos e 
com a assinatura dos Tratados de Westfália, consolidou-se a "territorialização" da política, que já vinha sendo tendência desde os séculos XII e XIII na Europa (CASTRO, 2001, p.07).

A política, dessa maneira, que antes se costurava por valores religiosos, laços sanguíneos, comunhão de tradições passou, com a ordem westfaliana, a seguir uma lógica territorial. A institucionalização espacial da política permitiu que fosse possível distinguir, desde então, entre a política interna - voltada para assuntos domésticos - e a política externa - dirigida para aspectos exteriores ao território do Estado (CASTRO, 2001).

A pesquisa optou em eleger o conceito de política externa empregado por Marcel Merle (1985) por acreditar que seja a mais sucinta e completa. De acordo com Merle (1985, p. 260): "A Política Externa é constituída por um conjunto de iniciativas que emanam do ator estatal, tendo em vista mobilizar para o serviço o máximo de fatores disponíveis tanto no ambiente interno quanto no ambiente externo".

Tendo em mente que a política externa não é somente dirigida por questões internacionais, mas, também, por particularidades nacionais orientadas pelo Estado, é evidente que as diversidades de políticas externas obedecem à mesma lógica das pluralidades sociais e políticas dos próprios Estados-nação. Se a segurança internacional é um dos temas considerados high politics pelas nações centrais, o desenvolvimento econômico é com certeza o tema medular nos Estados que compõem a periferia do sistema econômico internacional.

O primeiro intelectual a estudar o papel do Estado como elemento complementar ao desenvolvimento econômico foi o inglês William Petty (1623 - 1687). Em dois pequenos textos intitulados Tratado sobre impostos e contribuições de 1662 e o Aritmética política de 1690, Petty apresenta suas ideias sobre excedente econômico, divisão social do trabalho, avanço da produtividade em manufaturas e o investimento em infraestrutura como conjunto de práticas de política econômica determinante para a redução de custos de produção e para o aumento do poder internacional de cada país (PADULA, FIORI, 2019).

Posteriormente, no século XVIII, as formulações de Alexander Hamilton - primeiro secretário do tesouro dos Estados Unidos da América (EUA) - publicadas no Reports of the Secretary of the treasury on the subject of manufactures (1791) - conhecido como Relatório sobre as Manufaturas - apregoavam medidas econômicas protecionistas para estimular 0 mercado interno e para viabilizar a instalação e o desenvolvimento da indústria manufatureira estadunidense. Hamilton é considerado como o primeiro intelectual a estruturar uma retórica madura sobre a proteção da "indústria nascente".

Apesar dos estudos de Petty sobre excedente econômico e de Hamilton sobre protecionismo serem substanciais para a compreensão de estratégias desenvolvimentistas, foi somente no século XIX, com os escritos de Friedrich List na Alemanha que se estruturou 
formalmente um conjunto de ideias com clara proposta de expressar uma teoria com concepção de mundo realmente nacional desenvolvimentista.

List, em sua obra Sistema Nacional de Economia Política de 1841, ao analisar as experiências históricas de desenvolvimento econômico de países como Grã-Bretanha, Holanda, Portugal, Espanha, França, EUA, Estados italianos, das cidades da Liga Hanseática e da Alemanha; concluiu que a Grã-Bretanha foi o primeiro país a adotar uma sistemática política de proteção da indústria nascente, conquistando a supremacia tecnológica perante as demais regiões e Estados. Somente depois de realizar seu catching-up e transmutar suas vantagens comparativas, os ingleses passaram a advogar do livre-comércio (LIST, 1983).

Diante dessa conclusão, List estabeleceu que caberia ao Estado procurar desenvolver a infraestrutura, o poder político nacional, a segurança e a ordem nacional, além de investir em intelectuais, procurar a harmonia entre as leis e as instituições e, sobretudo, construir uma indústria diversificada, ativa e harmônica com o comércio e com a agricultura. List (1983, p.101) chama esse conjunto de ações de "forças produtivas da nação", sendo elas responsáveis não somente pela riqueza de um país, mas é a própria riqueza da nação.

A despeito de ter surgido embrionariamente na Europa com os estudos de William Petty no século XVII e de List no século XIX, foi na América Latina, conquanto, que o pensamento de desenvolvimento econômico se condensa e se consolida como uma consciência e categoria teórica econômica, especialmente após os estudos da Comissão Econômica para América Latina e Caribe da Organização das Nações Unidas (CEPAL-ONU) no final dos anos 1940 e começo dos anos de 1950.

Com a criação da CEPAL-ONU no Chile em 1948, os pensadores latino-americanos começaram a contribuir mais ativamente para as teorias do desenvolvimento econômico. Autores como Prebisch e Furtado, percussores do pensamento cepalino, em um primeiro momento, associaram o desenvolvimento econômico à intencionalidade política. Prebisch operacionaliza o conceito de política de desenvolvimento da seguinte forma:

[...] significa um esforço deliberado de atuar sobre as forças da economia a fim de acelerar seu crescimento, não pelo crescimento mesmo, mas como meio de conseguir um melhoramento persistente da renda nos grupos sociais de rendas inferiores e médias e sua participação progressiva na distribuição da renda global (PREBISCH, 1961, p. 35).

De acordo com Fonseca (2015), os autores latino-americanos até meados de 1960 possuíam uma ideologia desenvolvimentista, particularmente Celso Furtado, Raul Prebisch e Roberto Simonsen, contudo não tinham uma teoria econômica acerca do desenvolvimento econômico de fato. Os primeiros autores a direcionarem seus estudos no intento de formular e 
de operacionalizar o conceito de desenvolvimento econômico foram Hélio Jaguaribe em seu livro Desenvolvimento econômico e desenvolvimento político (1962) e Bresser-Pereira em seu artigo $O$ empresário industrial e a revolução brasileira (1963).

Segundo Jaguaribe (1969, p.13): "[...] o processo de desenvolvimento econômico é um processo de crescimento da renda real caracterizado pelo melhor emprêgo dos fatôres de produção, nas condições reais da comunidade e ideias do tempo". Para Bresser-Pereira (1963, p.17), o desenvolvimento econômico é: "Um determinado grau de intervenção do Estado na economia, planejando-a e realizando investimentos em setores básicos como os serviços públicos, a indústria do aço, do petróleo [...] na promoção do desenvolvimento nacional".

Bresser-Pereira, que foi um dos precursores dos estudos acerca do desenvolvimento econômico na América Latina e que continua em intensa produção acadêmica atualmente formulou, em 2016, um conceito de desenvolvimento econômico que praticamente sintetiza todas as suas concepções anteriores. Para o autor:

O desenvolvimento econômico é o processo de acumulação de capital com incorporação de progresso técnico que resulta em transformações estruturais da economia e da sociedade e no aumento dos padrões de consumo de um Estadonação. É um processo histórico que ocorre a partir da revolução capitalista e, particularmente, da revolução industrial; é o aumento continuado da produtividade, que implica uma sofisticação cada vez maior da mão de obra empregada na produção. [...]. Por isso, o desenvolvimento significa industrialização ou, mais amplamente, sofisticação produtiva [...] (BRESSERPEREIRA, 2016, p.111).

Se em um espectro existe o desenvolvimento econômico, em outro há o subdesenvolvimento. A condição de subdesenvolvimento é atribuída por Celso Furtado, formulador da Teoria do Subdesenvolvimento, a uma configuração específica dos países periféricos à economia capitalista que se reproduz em diferentes níveis de crescimento não como etapa histórica comum a todos os países, mas como resultado autossustentado histórico da evolução da economia industrial moderna. A consolidação de uma estrutura produtiva industrial na Europa, liderada pela Grã-Bretanha, após a Revolução Industrial, segundo Furtado (1992), condicionou o desenvolvimento econômico de quase todas as demais regiões do planeta.

O subdesenvolvimento das economias periféricas, desse modo, é consequência de uma trajetória histórica do capitalismo que fez com que houvesse países desenvolvidos e países subdesenvolvidos. De acordo com Furtado (1992, p.8), “[...] o subdesenvolvimento é um desequilíbrio na assimilação dos avanços tecnológicos produzidos pelo capitalismo industrial a favor das inovações que incidem diretamente sobre o estilo de vida".

No processo de compreender o subdesenvolvimento e de elaborar estratégias para superar essa condição da América Latina, pensadores da região produziram vultoso material 
acerca do desenvolvimento econômico. O avanço teórico científico e a percepção de mundo apresentadas por essas referências impactaram expressivamente na estruturação da política externa no Brasil, proporcionado a edificação de verdadeiros paradigmas nesta política de Estado na leitura de Amado Cervo.

\section{OS PARADIGMAS NA POLÍTICA EXTERNA BRASILEIRA PARA O DESENVOLVIMENTO ECONÔMICO}

Na segunda metade do século XX, o físico e filósofo Thomas Kuhn revolucionou a epistemologia e a história da ciência. O autor questionou a visão positivista, as teorias mecanicistas e deterministas a respeito do mundo físico, do cosmos e das sociedades humanas. Elas afirmavam que os avanços científicos são acumulativos e ocorrem de forma contínua. Kuhn (1998), autor considerado um dos fundadores da tendência histórico-sociológica na filosofia da ciência, afirma que as evoluções se dão de forma descontínua e por meio de grandes rupturas científicas, assinalando o surgimento de novos paradigmas. "O desenvolvimento teórico não é um processo isolado, mas episódios prolongados, dotados de uma estrutura que reaparece regularmente" (KUHN, 1998, p.78).

Etimologicamente, o termo paradigma tem origem no grego paradeigma que significa modelo ou padrão. É a representação de um padrão a ser seguido, a algo que serve de modelo ou exemplo em determinada situação. É um conceito das ciências e da epistemologia que define um exemplo típico ou modelo de algo. Kuhn operacionaliza paradigma como "[...] as realizações científicas universalmente reconhecidas que, durante algum tempo, fornecem problemas e soluções modelares para uma comunidade de praticantes de uma ciência" (KUHN, 1998, p.13). Para Kuhn (1998), dessa maneira, paradigma seria um "modelo" ou "padrão" compartilhado pelos membros de uma comunidade; inversamente, uma comunidade consiste nas pessoas que partilham desse paradigma. No caso de uma comunidade científica, ele é o referencial para as investigações, para as pesquisas.

A compreensão de paradigma como sistemas de ideias, de modelos e de padrões para uma comunidade permite inferir que há diferentes paradigmas. Em determinado momento um paradigma pode ser dominante enquanto outros permanecem na resistência ou são praticamente descartados. Para Kuhn (1998), a passagem de um paradigma para outro possibilitaria o avanço teórico, científico e o surgimento de uma nova percepção de mundo. Esse movimento desencadearia a superação de valores e dos próprios paradigmas estabelecidos, viabilizando que a comunidade chegue a uma concepção cada vez mais próxima do real. 
No Brasil, Amado Cervo (2008) identifica quatro paradigmas que orientaram as relações internacionais do país desde sua independência. São eles: liberal-conservador (século XIX até 1930); desenvolvimentista (1930 - 1989); e por último, dois que estão em disputa para tornaremse dominantes, o neoliberal (1990 - 2002) e o logístico (2003 - 2016).

O paradigma desenvolvimentista da política externa brasileira teve seu início com a Revolução de 1930, que colocou Getúlio Vargas no poder. A busca pela superação do paradigma liberal-conservador - focado na diplomacia agroexportadora influenciada pelo sistema de ideias da economia ricardiana das vantagens comparativas que vigorava desde o século XIX - ganhou força com a ascensão do pensamento keynesiano-desenvolvimentista no mundo. A crise de 1929 fez com que os Estados conquistassem nova relevância como atores econômicos. Se nos países centrais o crash da Bolsa de Nova lorque em 1929 direcionou os governos a adotarem medidas protecionistas, maior amparo social e nacionalismo; nos países latino-americanos fez com que os Estados tomassem a dianteira no processo de modernização ao incorporar o paradigma desenvolvimentista (CERVO, 2008; CERVO, BUENO, 2002).

Johnson (1982) afirma que o Estado desenvolvimentista - como os que existiram na América Latina em grande parte do século XX - não pode ser puramente organizador do mercado em um modelo unicamente keynesiano - igual nas economias centrais - pois é incapaz de retirar a economia do subdesenvolvimento. O Estado desenvolvimentista, para Johnson (1982), está preocupado com a efetividade das capacidades produtivas enquanto o Estado regulador busca somente maior eficiência da economia. O Estado regulador não planeja, não executa e tampouco controla política industrial, por exemplo. No Estado desenvolvimentista a política industrial, por sua vez, é prioridade.

O chancelar Oswaldo Aranha pode ser considerado como principal responsável pela inserção do referencial desenvolvimentista na política externa brasileira durante o período Vargas. Ex-embaixador do Brasil em Washington e Ministro das Relações Exteriores (1938-1944), Oswaldo Aranha tinha bastante liberdade para a elaboração da política externa brasileira. Durante sua chancelaria, o Ministério das Relações Exteriores (MRE) procurou reorientar a política externa para que conseguisse ganhos recíprocos nas relações internacionais, possibilitando, assim, executar um projeto nacional de desenvolvimento econômico assertivo com o escopo de superar as desigualdades entre as nações. Um dos pontos altos da política externa de Aranha e da consolidação do paradigma desenvolvimentista foi a adoção de uma diplomacia pendular entre EUA e Alemanha (CPDOC/FGV-RJ. Arquivo Oswaldo Aranha, 1938.01.07 cpl5).

De acordo com Caldas (1996), a política externa brasileira desde 1934 foi caracterizada pela atitude de obter ganhos da rivalidade entre as principais potências econômicas mundiais da época. A diplomacia pendular possibilitou com que o Brasil afirmasse contratos de exportações e 
de cooperação mais vantajosos para seu desenvolvimento tanto com os EUA quanto com a Alemanha. O Brasil conseguiu, por exemplo, aproveitar o "comércio compensado" ${ }^{2}$ com a Alemanha ao mesmo tempo que usufruía da cláusula de "nação mais favorecida" estabelecida com os EUA, que reduziram ou até mesmo isentaram produtos importantes na pauta de exportação do Brasil, como o café e o cacau (CERVO, BUENO, 2002, p. 254-255).

O auge da diplomacia pendular foi o acordo entre Brasil e EUA em 1940 para construção da Companhia Siderúrgica Nacional em Volta Redonda. Além da obtenção de créditos suplementares para a exploração da indústria de matérias-primas brasileiras e pela concessão de um fundo de US\$200 milhões para as forças armadas nacionais adquirirem armas nos EUA por meio do lend-lease. Em contrapartida, os EUA obtiveram o apoio brasileiro na Segunda Guerra Mundial (MOURA, 1980).

Se, na prática, Oswaldo Aranha e Getúlio Vargas são os pioneiros a adotarem instrumentos diplomáticos almejando o desenvolvimento nacional, o bloco teórico-intelectual que deu alicerce para o sistema de ideias, o avanço científico e para concepção do paradigma desenvolvimentista esteve praticamente concentrado na CEPAL/ONU e no Instituto Superior de Estudos Brasileiros (ISEB) no Rio de Janeiro.

O pensamento econômico da CEPAL de 1948 a 1990 tinha como retórica a defesa do Estado-empreendedor para alcançar o desenvolvimento econômico. Os principais pensadores cepalinos dessa época são: Celso Furtado, Jorge Ahumada, Aníbal Pinto, Cristóbal Lara, José A. Mayobre, Manuel Balboa, José Medina Echavarria, Victor Urquidi, David Pollock, Louis Swenson e Osvaldo Sunkel. O ISEB atuou de 1955 a 1964 como um respeitável centro de produção e de promoção do nacional desenvolvimentismo, contando com renomados autores como: Hélio Jaguaribe, Alberto Guerreiro Ramos, Antonio Cândido, Wanderley Guilherme dos Santos, Ignácio Rangel, Cândido Mendes, entre outros. Esses autores e instituições - com estudos originais e o inédito método histórico-estruturalista com interpretações sobre centro-periferia, indústria, mercado interno, renda salarial, deterioração dos termos de troca, defasagem tecnológica, nacionalismo - influenciaram significativamente a política externa brasileira até 1980.

Segundo Amado Cervo, o paradigma desenvolvimentista na política externa brasileira apresenta, em suma, as seguintes características.

[...] a) consciência da transição; b) desenvolvimento como vetor da política externa; c) realismo de conduta. E confere nova funcionalidade ao setor externo, inventando o modelo de inserção internacional à luz de três outras noções de fim: a) realizar interesses de uma sociedade complexa; b) conceber desenvolvimento como expansão da indústria; c) prover de eficiência a política exterior mediante autonomia decisória, cooperação externa, política de comércio exterior flexível e

\footnotetext{
${ }^{2}$ Sistema de importação e exportações feitas à base de troca de mercadorias, cujos valores eram contabilizados nas "caixas de compensação" de cada país (CERVO, BUENO, 2002, p.254).
} 
não doutrinária, subordinação da política de segurança, isto é, da guerra e da paz, aos fins econômicos e negociações simultânea com os grandes e os vizinhos (CERVO, 2008, p.72).

Os principais governantes brasileiros que ajudaram a estruturar e foram influenciados por essa comunidade e seus referenciais, segundo Cervo (2008), foram: Getúlio Vargas (19301945/1951-1954), Juscelino Kubitschek (1956 - 1961) e Ernesto Geisel (1974-1979) cada um com suas particularidades e singularidades. Vargas usou da poupança interna, dos estímulos estatais e enfrentou a crise cambial em virtude do estrangulamento externo para garantir o emprego e a demanda agregada. Juscelino e Geisel contaram com apoio do capital estrangeiro e permitiram maior concentração de renda, obtendo, assim, muito mais crescimento econômico do que desenvolvimento econômico.

$\mathrm{Na}$ década de 1960, o paradigma desenvolvimentista da política externa brasileira e o método histórica-estruturalista cepalino ganharam novos avanços teórico-científicos. A comunidade contou com os estudos da Teoria da Dependência. Autores como Theotonio dos Santos, Ruy Mauro Marini, Gunder Frank, Vânia Bambirra, Orlando Caput e Roberto Pizarro, com forte influência marxista; e Fernando Henrique Cardoso e Enzo Faletto, vertente weberiana, enfatizaram que a estratégia de industrialização per se não produziria desenvolvimento sustentado nos países periféricos em razão da permanência das condições econômicas e sociais preexistentes.

Para a Teoria Marxista da Dependência (TMD), os meios de produção capitalistas foram entendidos como um sistema mundial hierarquizado, monopólico e desigual que produz e reproduz padrões nacionais com diferentes formas de acumulação primitiva de capital. Esse conjunto de categorias cria centros mundiais de acumulação central e regiões que se configuram como dependentes nesse processo global de transferência de valor que gera um círculo vicioso no antagonismo centro-periferia. Enquanto os centros tendem a desenvolver sua base tecnológica e industrial, baseando sua produção na mais-valia relativa, os países dependentes amparam seus padrões de acumulação na superexploração da força de trabalho. A periferia, dessa maneira, sempre se manteria em um modelo capitalista mercantil, com acumulação débil de capital e nunca solidificaria sua burguesia nacional. Para a TMD, não haveria outro caminho para o desenvolvimento senão a revolução socialista (MARINI, 2000; FRANK, 1980; MARTINS, 2011).

Para a Interpretação da Dependência weberiana, representada por Fernando Henrique Cardoso e Enzo Faletto, o desenvolvimento tem essencialmente duas dimensões: uma interna e outra externa. Enquanto a primeira é o resultado da relação entre as classes sociais de um país e gera um produto socioeconômico, a segunda concerne as relações que se estabelecem entre os grupos dominantes e o resto do mundo. Os sistemas econômicos e políticos funcionariam de 
forma orquestrada, fazendo com que na dependência houvesse uma ambiguidade, isto é, autonomia política, mas dependência econômica. Realizando um rearranjo político-social na dimensão interna e uma integração associada aos países centrais na dimensão externa. $O$ desenvolvimento, segundo essa interpretação, seria viável dentro do próprio sistema capitalista (CARDOSO, FALETTO, 2004).

O sistema de ideias da TMD alcançou prestígio entre os intelectuais latino-americanos e entre os mandatários da política externa brasileira, sobretudo os chanceleres: Afonso Arinos de Melo Franco (janeiro de 1961 a agosto de 1961 - julho de 1962 a setembro de 1962); San Tiago Dantas (setembro de 1961 a julho de 1962) e João Augusto de Araújo Castro (agosto de 1963 a março de 1964). Conhecidos como independentistas, esses chanceleres entendiam que somente a industrialização não retiraria o Brasil do subdesenvolvimento. Era preciso reestruturar o sistema internacional. Os independentistas recomendavam o desenvolvimento via emancipação econômica, acompanhado da desideologização da política externa, de não intervenção e de coexistência pacífica dos regimes capitalistas e socialistas marxistas, bem como a solidariedade entre as nações periféricas para ganhos de capital e de tecnologia. Era o Pensamento Independentista que nascia dentro do paradigma desenvolvimentista da política externa brasileira.

O Brasil, segundo esses pensadores, não tinha a obrigatoriedade de se alinhar irrestritamente e norteado por valores ideológicos a determinado país central sem antes avaliar os ganhos políticos, econômicos e sociais dessa parceria. Tais medidas foram executadas durante os governos de Jânio Quadros (31 de janeiro de 1961 a 25 de agosto de 1961) e de João Goulart (08 de setembro de 1961 a 02 de abril de 1964) e ficaram conhecidas como: Política Externa Independente (PEI) (CERVO, 2008; CERVO, BUENO, 2002).

A transição de paradigma na política externa brasileira somente ocorreria na década de 1980 com o avanço do neoliberalismo econômico e suas soluções de austeridade fiscal e monetária como ferramentas para o desenvolvimento. No final da década de 1980, o Estado desenvolvimentista, que vinha sendo financiado pelo governo ditatorial civil-militar brasileiro (1964 - 1985) com capital de reciclagem dos petrodólares, entra em decadência e passa por uma severa crise. O modelo estava sofrendo fortes pressões desde a flexibilização do sistema Bretton Woods em 1971 e com o choque do petróleo de 1973 (GREMAUD, VASCONCELLOS, TONETO JR., 2007).

O resultado de diferentes fatores - internos e externos - fez com que houvesse um forte período recessivo na década de 1980 no Brasil. Inflação galopante, desequilíbrios nas contas públicas, desemprego e falta de legitimidade política foram minando o apoio que a ditadura civilmilitar possuía. Em 1985, o Brasil começou seu processo de redemocratização e os militares 
cederam os principais cargos dos poderes executivos para os civis. Os governos que se seguiram - José Sarney (1985 - 1989); Fernando Collor de Mello (1990 - 1992); Itamar Franco (1992 - 1994) e Fernando Henrique Cardoso (1995 - 2002); tiveram como principal meta conter a inflação.

Em 1989, o Consenso de Washington preconizou como solução para a crise e para a superação do subdesenvolvimento, por parte dos países periféricos, a adoção de medidas liberalizantes e ortodoxas na economia. O sistema de ideias do neoliberalismo tem suas origens, sobretudo, nos EUA com os estudos de Milton Friedman e George Stigler, protagonistas dos economistas monetaristas da Escola de Chicago. A concepção de mundo do neoliberalismo fundamenta-se na revalidação de preceitos liberais e na superação de valores desenvolvimentistas e keynesianos na economia. O referencial neoliberal reafirma a promoção da liberdade das forças impessoais e neutras do mercado na alocação e na distribuição eficiente dos recursos produtivos entre os agentes sociais. Segundo seus autores, a preservação dos valores individuais, comerciais, financeiros e de investimento dos empreendedores é o principal mecanismo para a geração de riquezas, desenvolvimento tecnológico e, por conseguinte, aumento geral do bem-estar social (CASTELO, 2013).

O pensamento econômico neoliberal, que já possuía base histórica e social local no Brasil em virtude do liberalismo econômico vigente pré-1930, modificou a organização da formulação da política externa brasileira e a inserção internacional do país. A interpretação de mundo histórico-estruturalista, a leitura dual das relações internacionais entre centro e periferia e o incentivo ao conserto da ordem internacional foram substituídos pela interpretação ricardiana de vantagens comparativas com sua divisão internacional do trabalho, a leitura da globalização com seus benefícios do livre mercado global e o incentivo à unificação dos fatores transnacionais do capitalismo (CERVO, 2008).

O paradigma neoliberal chegou ao poder com a eleição de Fernando Collor de Mello em 1989 e a subida de Francisco Rezek como chanceler do Brasil. É, todavia, com Celso Lafer duas vezes Ministro das Relações Exteriores (abril de 1992 a outubro de 1992 - janeiro de 2001 a 2003) - com Luiz Felipe Lampréia - Ministro das Relações Exteriores (1995 - 2001) e com Fernando Henrique Cardoso - Ministro das Relações Exteriores (outubro de 1992 a maio de 1993), Ministro da Fazenda (maio de 1993 a março de 1994) e Presidente da República Federativa do Brasil de 1995 a 2002, que o paradigma neoliberal ganhou corpo e solidificou-se na política externa.

Os principais formuladores do paradigma neoliberal das Relações Internacionais no Brasil são diplomatas e acadêmicos: Eduardo Viola, Carlos Pio, Paulo Roberto de Almeida, José Botafogo, Rubens Barbosa, Rubens Ricupero, Roberto Abdenur, entre outros, além dos já 
citados Cardoso, Rezek, Lafer e Lampréia. O pensamento de Cardoso e de sua equipe nortearam o paradigma neoliberal na política externa brasileira por mais de uma década, buscando o desenvolvimento econômico não mais mediante Estado-empreendedor, no entanto via poupança externa e autonomia pela integração.

A autonomia pela integração, segundo Lampréia (1998), tem como objetivo almejar o desenvolvimento econômico por meio da adaptação do Brasil às normas e aos regimes internacionais. A estratégia é adaptar-se institucionalmente a economia brasileira às regras e às diretrizes dos países centrais, conquistando, assim, maior credibilidade externa e atraindo investimento das transnacionais e das multinacionais oriundas dos países desenvolvidos. A autonomia pela integração visa superar o Pensamento Independentista e terceiro-mundista com sua dicotomia centro-periferia na política externa brasileira, porquanto "[...] o mundo 'globalizado' funciona, cada vez mais, com base em avaliações de confiabilidade e, inversamente, de risco" (LAMPRÉIA, 1998, p. 13).

A eliminação do modelo Estado desenvolvimentista, a abertura do mercado, do sistema produtivo nacional e a valorização do privado em detrimento do público - realizados durante os mandatos de Fernando Henrique - estariam inseridos, na visão do Ex-presidente e sua equipe, na necessidade de modernizar politicamente e economicamente a sociedade brasileira como condição para inserir-se competitivamente no processo de globalização. Para Cardoso (1991), o desenvolvimento econômico brasileiro em plena Era Global - que impõe circunstâncias imperantes e implacável estratégia sem alternativas - teria de sofrer mudanças.

Cardoso, consequentemente, pregava a entrada de fatores externos do capitalismo no Brasil e a resignação às normas e às pautas de conduta da gestão da ordem mundial como mecanismos para promover o desenvolvimento à época da globalização. A atuação de Cardoso na política não foi contraditória com seus preceitos sobre Dependência da década de 1960-70. Os trabalhos de Cardoso sempre afirmaram que o desenvolvimento econômico seria viável dentro do sistema capitalista desde que o país realizasse reformas internas e integração externa. É por isso que o pensamento de Cardoso pode ser definido como dependente-associado. A obra Dependência e desenvolvimento na América Latina de 1967 de Cardoso e Faletto, para Traspadini (2014), tinha como argumento central de que o desenvolvimento dependente e associado são preceitos incipientes de uma defesa pela busca da interdependência dos países latino-americanos com as nações centrais.

De acordo com Bastos e Hiratuka (2017), o paradigma neoliberal na política externa brasileira: 
internacional poderia levar não à regressão econômica, mas ao desenvolvimento, desde que o país periférico fosse capaz de atrair filiais estrangeiras com um ambiente de negócios local propício, criando um modelo de desenvolvimento dependente e associado (BASTOS, HIRATUKA, 2017, p. 04-05).

A lógica por trás do paradigma neoliberal nas Relações Internacionais é simples, o país segue as regras da política internacional, fortalece as instituições, investe em eficiência e capacitação, normaliza sua economia, logo começaria a receber investimentos estrangeiros e a ser convidado a se inserir gradativamente como protagonista, que seja secundário ou auxiliar, na economia e na política internacional. O crescimento do país somente seria possível via poupança externa. Dessa maneira, restava ao Brasil uma forma de dependência associada aos países centrais que poderiam levar o país para o desenvolvimento econômico dentro do capitalismo mundial e a uma maior inserção internacional (CERVO, 2008; VIGEVANI, OLIVEIRA, CINTRA, 2003).

Fiori (2001, p.55) denomina essa lógica de pensar de "cosmopolitismo de cócoras". Esse é caracterizado por uma relação disfuncional, isto é, uma das partes não tem capacidade de administrar seu próprio desenvolvimento. Segundo Moraes, Aguiar e Tauil (2018), esse modelo de crescimento pautado na poupança externa e nos preceitos econômicos vindo do exterior faz com que o país perca sua capacidade de traçar seu próprio projeto de sociedade, interferindo, inclusive, em sua própria identidade. A posição passiva do Estado na relação com os investimentos externos gera efeito contrário do desejado, uma vez que aprofunda estruturalmente a condição de subdesenvolvimento ao descolar o centro de decisão econômica do Estado-nacional para as empresas multinacionais, transnacionais, por conseguinte, para a burguesia internacional e outros Estados. De acordo com Fiori:

É importante, entretanto, que se tenha claro que essa tutela não foi mera imposição externa; correspondeu a uma opção interna [...] de nossas elites econômicas e políticas, comandadas hoje por uma aliança bem-sucedida entre o "cosmopolitismo de cócoras" de uma parte da intelectualidade paulista e carioca atrelada às "altas finanças internacionais" e o "localismo" dos donos do "sertão" e da "malandragem" urbana brasileira. Essa aliança de poder está levando até suas últimas consequências um projeto de inserção internacional e de transnacionalização radical de nossos centros de decisão e das estruturas econômicas brasileiras (FIORI, 2001, p.57).

O paradigma neoliberal na política externa brasileira, portanto, não está preocupado em construir a autonomia ou a independência, pois acredita que em virtude da globalização o que existe, atualmente, é uma interdependência complexa - conforme apresentam Keohane e Nye (2012) - regida pelas instituições e pelos regimes internacionais. As economias centrais são as responsáveis por patrocinarem essa "nova ordem mundial”, então o Brasil tem de procurar uma relação mais estreita com seus principais atores, isto é, EUA e UE. 
Para o paradigma neoliberal, o mundo contemporâneo global é personalizado pela descentralização, pela institucionalização e pela interdependência. Se há descentralização e todos os atores são iguais, não há lógica em estabelecer uma divisão dualista entre centroperiferia, se há uma complexa interdependência, por consequência não há autônomos vs. dependentes. O que há é complementariedade das economias estabelecida pela divisão internacional do trabalho e pelas vantagens comparativas de cada nação.

Os ganhos políticos e econômicos dessa inserção internacional, pautada no paradigma neoliberal, não foram os esperados. As expectativas, de certo modo idealistas de Cardoso e sua equipe de transformarem o Brasil em uma nação desenvolvida por meio da associação com o capital externo e de ganharem protagonismo internacional via institucionalização e via regimes não se concretizaram. O Brasil continuou economicamente subdesenvolvido e politicamente coadjuvante ou até mesmo mero figurante nos temas high politics da política internacional, com exceção na temática ambiental.

Para Amado Cervo os impactos do paradigma neoliberal na política externa brasileira podem ser resumidos em um positivo e dois negativos. São eles:

O choque da abertura despertou empresários brasileiros dos setores público e privado, acomodados que andavam ao abrigo de um protecionismo exacerbado a que havia conduzido o paradigma anterior. [...] Com a abertura, para fazer face à inundação de produtos estrangeiros, foram forçados a modernizar suas plantas e métodos. A resposta foi positiva e desse modo, o choque da abertura contribuiu para elevar a produtividade sistêmica da economia brasileira [...] Os impactos negativo se concretizam, por outro lado, com o aprofundamento de dependência estruturais e, por outro, com o regresso histórico. [...] Dependências financeira, empresarial e tecnológica, promovidas novamente, elevaram a vulnerabilidade externa do País a níveis críticos: dívida, enfraquecimento empresarial e fechamento de centros de pesquisa e inovação. Ao empurrar, ademais, a economia de matriz nacional para o setor primário [...] (CERVO, 2008, p.81-82).

O ceticismo perante a globalização de mercado, que aconteceu de forma assimétrica, as críticas aos preceitos neoliberais e a ilusória interdependência complexa estavam presentes há anos nos movimentos sociais, políticos e acadêmicos que vinham reformulando o sistema de ideias do pensamento crítico latino-americano, independentista, desenvolvimentista e resistindo ao avanço do paradigma neoliberal. Nas eleições de 2002 no Brasil, os maiores representantes dessa reconstrução e resistência estavam alinhados com o candidato à Presidência da República pelo Partido dos Trabalhadores (PT) e que foi eleito, Luís Inácio Lula da Silva. De acordo com Bastos e Hiratuka:

A crítica fundamental à "autonomia pela integração" era que o governo FHC abdicara da construção de um projeto de desenvolvimento definido e coordenado pelo Estado nacional, transferindo decisões centrais ao destino do país para 
organismos internacionais, grandes grupos multinacionais e especuladores financeiros, ao aderir ao receituário neoliberal. Diante da adesão ao ideário neoliberal, o espaço para a atuação da diplomacia econômica diminuía, como, aliás, aconteceria com a intervenção estatal em geral: tratava-se basicamente de defender alguns interesses particulares eventualmente afetados pela estratégia de abertura, sem questionar a ordem internacional assimétrica que os países desenvolvidos buscavam consolidar por meio de tratados multilaterais e da difusão de ideologias que lhes seriam favoráveis (BASTOS, HIRATUKA, 2017, p. 06).

Com a vitória de Lula nas eleições, segundo Amado Cervo (2008), surge um novo paradigma na política externa brasileira influenciado pelos estudos econômicos e almejando o desenvolvimento: o paradigma logístico. Esse tem seu berço, na comunidade cientifica, especialmente no Instituto de Relações Internacionais da Universidade de Brasília (UnB). Pesquisadores como: Moniz Bandeira, José Flávio Sombra Saraiva e Amado Cervo estruturaram diversas interpretações acerca do uso da política externa como instrumento de desenvolvimento econômico. Em outros centros de pesquisas havia também importantes contribuições como de: José Luís Fiori (UFRJ), Paulo Fagundes Vizentini (UFRGS), Paulo Nogueira Batista Jr. (FGV), Gilberto Dupas (USP), Tullo Vigevani (UNESP), etc.

No Itamaraty, expoentes embaixadores mostravam-se insatisfeitos com o paradigma neoliberal, principais nomes eram: Celso Amorim, Luiz Augusto Souto Maior e Samuel Pinheiro Guimarães. Intelectuais próximos ao PT como Marco Aurélio Garcia e Glauco Antônio Truzzi Arbix, ademais, foram os principais defensores do paradigma logístico como caminho para romper com o subdesenvolvimento brasileiro.

Além desses, muitos atores do primeiro escalão dos governos petistas estavam edificando um novo sistema de ideias para uma nação almejar o desenvolvimento econômico: o Social desenvolvimentismo. O Social desenvolvimentismo evoluiu academicamente a partir dos estudos da Teoria Desenvolvimentista Clássica, surgindo embrionariamente em 1990 no artigo $O$ Brasil a caminho do mercado de consumo de massa de Antônio Barros de Castro, professor emérito da UFRJ e ex-presidente do Banco Nacional de Desenvolvimento Econômico e Social (BNDES). Contudo, o campo teórico e retórico do Social desenvolvimentismo se enraíza no Instituto de Economia da Universidade Estadual de Campinas (IE-Unicamp) balizado em torno do Centro de Estudos de Conjuntura e Política Econômica (CECON) e da Rede Desenvolvimentista (Rede D). Há, ainda, contribuições significativas de economistas da UFRJ e de destacados intelectuais da Argentina, do México e do Uruguai.

Na visão do Social desenvolvimentismo, qualquer nova política econômica de conteúdo desenvolvimentista tem de atentar para duas dimensões distintas e articuladas do Estado e do mercado: a doméstica e a internacional. Em âmbito doméstico, o Social desenvolvimentismo apregoa um crescimento econômico via aumento da participação dos salários na renda nacional 
e investimento em infraestrutura social e econômica, ou seja, um regime de crescimento wage investment-led growth strategy (BASTOS, 2012; BIELSCHOWSKY, 2012; CARNEIRO, 2012; BIANCARELLI, ROSSI, 2014).

$\mathrm{Na}$ dimensão internacional, o Social desenvolvimentismo opta por uma política externa ativa e altiva (PEAA), que resgata valores da PEI. A PEAA - apresentada em diversos textos e discursos Amorim (2004, 2015); Guimarães (2006, 2010); Cervo (2008); Garcia, (2010); Bastos e Hiratuka (2017) - defende a intervenção do Estado para uma inserção internacional menos condicionada a crises e com o foco no desenvolvimento econômico e social sustentável em longo prazo.

Para Mercadante (2010), a PEAA do Social desenvolvimentismo é caracterizada pelos seguintes pontos: i) promoção do desenvolvimento nacional; ii) superação da vulnerabilidade externa por meio de superávits comerciais; iii) comércio exterior como estímulo à produção interna e não somente para controle de preços e estabilidade monetária; iv) promoção da ordem mundial multipolar de forma realista e pragmática; v) eixo Sul-Sul como prioritário, sem excluir a importância do eixo Norte-Sul; vi) forte regionalismo e ativismo bilateral; vii) o princípio de nãoindiferença é tão importante quanto o princípio de não-intervenção; viii) autonomia pela diversificação, busca de novas parcerias e espaços econômico-políticos.

No paradigma logístico nas Relações Internacionais que norteia a PEAA, segundo Cervo (2008), o Estado tem de ser forte e ter capacidade de orientar as atividades econômicas, inclusive a internacionalização das empresas nacionais e a construção das empresas da América Latina, as denominadas translatinas. O estado, entretanto, não precisa ser necessariamente empreendedor, basta ser apoiador.

[...] o paradigma logístico, como experiência brasileira e latino-americana, comprova uma criatividade ainda maior. Recupera a autonomia decisória da política exterior [...] implementando um modelo de inserção pósdesenvolvimentista. Seu escopo final, a superação de assimetrias entre as nações, ou seja, elevar o patamar nacional ao nível das nações avançadas (CERVO, 2008, p.85-86).

De acordo com Cervo (2008), para o paradigma logístico, o sistema econômico internacional é dualista, ou seja, há um centro e uma periferia. A política externa brasileira tem o papel de ser ferramenta de superação das dependências estruturais - financeira, empresarial e tecnológica impostas pelas economias centrais e que inviabilizam o desenvolvimento econômico das economias periféricas. A racionalidade da economia internacional, a transnacionalização do capital externo e a inserção dos países periféricos na economia-mundo e no processo de globalização de forma passiva são fatores de desestabilização do Estado desenvolvimentista no 
âmbito interno. É preciso reestruturar o sistema econômico e político internacional, adotando uma interdependência econômica interestados real e não meramente discursiva.

Para tanto, as economias periféricas devem priorizar 0 modelo do Estado desenvolvimentista no âmbito interno e, na dimensão internacional o metacampo a ser construído tem de ter uma atuação logística. Em virtude das próprias limitações de atuação fora de sua soberania, o Estado desenvolvimentista ao atuar no âmbito internacional transmuta para Estado logístico e busca a autonomia pela diversificação (VIGEVANI; CEPALUNI, 2007).

De acordo com Cervo (2008), na sua atuação política o Estado logístico delimita três linhas claras de atuação: i) abandono da ilusão de mundo multilateral e harmonioso preconizados pelo paradigma neoliberal; ii) resgate da visão realista e prática dos independentistas; iii) busca da estruturação de um multilateralismo de reciprocidade entre países centrais e periféricos. $\mathrm{Na}$ questão econômica, o Estado logístico opera de dois modos: i) pela agregação dos empreendimentos nacionais às cadeias produtivas internacionais; ii) por investimentos direitos no exterior, inicialmente nos países vizinhos.

[...] o foco do paradigma (logístico) consiste, precisamente, em dar apoio logístico aos empreendimentos, o público e o privado, de preferência privado, com o fim de robustecê-lo em termos comparativos internacionais. Assim, procedem os governos dos países centrais - Estados Unidos, Europa e Japão, a título de exemplo - protegendo empresas, tecnologias e capital de matriz nacional, estimulando seu fortalecimento interno e sua expansão global, zelando pelo emprego e pelo bom salário dos trabalhadores, ampliando o bem-estar do consumidor (CERVO, 2008, p.87).

Com certa influência da Teoria Construtivista das Relações Internacionais, da Economia do Sistema-mundo, do Estruturalismo-histórico latino-americano e da Teoria Realista das Relações Internacionais, a formulação e a operacionalização do conceito de Estado logístico na política externa percebem a sociedade internacional como heterônima, e não como anárquica. Para essa visão, o processo de relacionamento interestados é contínuo e histórico, as identidades, a acumulação de capital e a estrutura produtiva não são estáticas, portanto, com possibilidades de serem modificadas. Busca-se, de acordo com Cervo (2008, p. 87), "[...] a construção de meios de poder e sua utilização para fazer valer vantagens comparativas, não mais naturais, mas intangíveis, como ciência, tecnologia e capacidade empresarial”.

A globalização para o Estado logístico tem de ser encarada de forma crítica e realista, inserindo-se ativamente na economia mundial. É preciso incentivar a internacionalização das camadas sociais produtivistas e suas grandes empresas nacionais para que elas adquiram vantagens de propriedade, permitindo o catching-up da economia periférica. A atuação do setor externo - para o paradigma logístico - auxilia as economias periféricas a gradativamente superar o subdesenvolvimento e a dependência econômica, produzindo bens e serviços intensivos com 
maior sofisticação produtiva e absorvendo mão-de-obra qualificada e tecnologia, consequentemente se desenvolvendo.

O paradigma logístico não busca o desenvolvimento econômico para o estabelecimento de um novo imperialismo, reproduzindo a divisão internacional do trabalho dualista vigente, mas para a adoção de uma interdependência econômica real e não ilusória e discursiva como a propagada pelo paradigma neoliberal. O modelo logístico discorda da visão de que a interdependência econômica já exista na atualidade e que o mundo já é multilateral e harmonioso. A real interdependência econômica, o real multilateralismo harmonioso nas relações internacionais - para o paradigma logístico - tem de ser ainda construídos e suas edificações passa necessariamente pelo desenvolvimento econômico das economias periféricas.

A ideologia subjacente ao paradigma do Estado logístico associa um elemento externo, o liberalismo, a outro interno, o desenvolvimentismo. Funde a doutrina clássica do capitalismo com o estruturalismo latino-americano. Admite, portanto, operar na ordem do sistema ocidental, recentemente globalizado. Na esfera política, o paradigma logístico [...] Recupera a autonomia decisória da política externa [...] Se escopo final, a superação de assimetrias entre as nações, ou seja, elevar o patamar nacional ao nível das nações avançadas. [...] A política exterior volta-se à realização de interesses nacionais diversificados [...] os logísticos consideram necessários, possíveis e convenientes os remédios de equilíbrio que estabelecem a interdependência real. [...] o comportamento logístico se depara, inicialmente, com o desafio de remover entulhos operacionais acumulados pela estratégia do liberalismo radical: atenuar a dependência tecnológica e financeira, promovendo a inovação produtiva e a saída da condição de esmoleiro internacional. E, com isso, restringir a vulnerabilidade externa (CERVO, 2008, p. 85-86).

Um dos pontos centrais do paradigma logístico executado pelo governo Lula foi a retomada do Pensamento Independentista, com as seguintes características: i) o Estado constitui um ator importante, central, mas não o único nas relações internacionais. Outros atores são considerados importantes, como Ols, ONGs, sindicatos, etc.; ii) a busca de uma cooperação simétrica no sistema internacional, reestabelecendo as relações inter-nações que são economicamente desiguais e caracterizada pela divisão internacional do trabalho por conta da relação de dominação-dependência entre economias centrais e periféricas; iii) o combate a massificação cultural imposta pelos países centrais, pois gera uma multiplicidade de dependências (social, cultural e política, além da econômica). No discurso de posse do Presidente Lula essas aspirações ficaram claras:

Nossa política externa refletirá, também, os anseios de mudança que se expressaram nas urnas. No meu Governo, a ação diplomática do Brasil estará orientada para uma perspectiva humanista e será, antes de tudo, um instrumento do desenvolvimento nacional. [...] Em relação à Alca, nos entendimentos entre o Mercosul e a União Européia, e na Organização Mundial do Comércio, o Brasil 
combaterá o protecionismo, lutará pela eliminação de barreiras e tratará de obter regras mais justas e adequadas à nossa condição de país em desenvolvimento. Buscaremos eliminar os escandalosos subsídios agrícolas dos países desenvolvidos, que prejudicam os nossos produtores, privando-os de suas vantagens comparativas. Com igual empenho, nos esforçaremos para remover os injustificáveis obstáculos às exportações de produtos industriais. Essencial em todos esses foros é preservar os espaços de flexibilidade para as nossas políticas de desenvolvimento nos campos social e regional, de meio ambiente, agrícola, industrial e tecnológico. Não perderemos de vista que o ser humano é o destinatário último dos resultados das negociações (Trecho do Discurso de Posse do Presidente Lula, 01 de janeiro de 2003).

Para os logísticos, o sistema internacional é sim dualista, ou seja, há um centro e uma periferia. A política externa brasileira tem o papel de ser a ferramenta de superação das dependências estruturais - financeira, empresarial, cultural e tecnológica. Os países periféricos têm de se unir, fortalecendo as relações Sul-Sul em vez da Norte-Sul para conseguirem reestruturar o sistema internacional ou atenuarem suas assimetrias. Não é por acaso que durante o governo Lula e Dilma Rousseff (2003 - 2016) houve várias iniciativas neste intento, por exemplo, a elaboração do Fórum BRICS (Brasil - Rússia, Índia, China e África do Sul), do Fórum IBAS (Índia, Brasil, África do Sul), a formação da Unasul (União de Nações Sul-americanas), a construção do Novo Banco de Desenvolvimento, além de forte atuação do BNDES e da Agência Brasileira de Promoção de Exportações e Investimentos (APEX-Brasil) nos países do sul.

A lógica é que a integração dos países da região, bem como a cooperação Sul-Sul possibilitariam aproveitar as brechas estruturais da relação centro e periferia, viabilizando uma atitude de ruptura com o neoliberalismo e com a própria dominação-dependência. Segundo o Celso Amorim:

Os princípios são os mesmos, mas as prioridades e agendas podem mudar. A política externa do governo do presidente Lula escolheu defender e avançar os interesses e valores brasileiros no mundo sem se furtar a prestar solidariedade aos países mais necessitados. Acreditamos que uma política externa solidária é ao mesmo tempo humanista e atende aos interesses brasileiros na medida em que um país é mais bem percebido quando contribui para a estabilidade global e para a redução das assimetrias entre os países. [...] A reforma da governança global é uma linha de força da atual política externa brasileira. Queremos contribuir para a construção de uma ordem internacional que seja mais justa, democrática e inclusiva para os países em desenvolvimento. A aproximação com outros países em desenvolvimento e a consequente universalização da nossa agenda externa são parte indissociável dessa estratégia (Trecho de entrevista do chanceler Celso Amorim ao IPEA, 08 de abril de 2010).

Em suma, o paradigma logístico pode ser caracterizado pela busca de maior independência aos centros de poder do sistema internacional, defesa de reformas das instituições internacionais, projeção ativa e autônoma, revisionismo da ordem internacional dividida entre Norte-Sul, desejo de que o Brasil possua maior liderança regional e relação mais 
próxima com os demais países do Sul. O paradigma logístico procura superar os valores do paradigma neoliberal ao mesmo tempo em que reestrutura o sistema de ideias e percepção de mundo do paradigma desenvolvimentista, podendo, portanto, ser considerado um avanço teórico e científico significativo na comunidade e na referência desenvolvimentista.

\section{CONSIDERAÇÕES FINAIS}

$\mathrm{O}$ artigo tentou demonstrar como que o pensamento econômico influenciou a política externa brasileira. A influência é tamanha que é possível categorizar os períodos da política externa do Brasil em paradigmas orientados por preceitos de determinadas teorias econômicas. Para a assimilação da preponderância da preocupação do desenvolvimento econômico na política externa brasileira, o artigo buscou explicitar a Análise Paradigmática das Relações Internacionais e seu debate atual. Demonstrou-se que não há dúvidas de que a preocupação com o desenvolvimento econômico brasileiro está intimamente correlacionada com a formulação e aplicação da política externa do país.

Ao analisar o paradigma desenvolvimentista (1930-1989), o neoliberal (1990-2002) e o logístico (2003-2016) verificou-se que cada um sofreu influência de correntes definidas do pensamento econômico. O paradigma desenvolvimentista da política externa brasileira sofreu influências do governo Vargas com a atuação do Aranha no MRE, da CEPAL, do ISEB, da TMD e do Pensamento Independentista. Nesse paradigma a política externa tinha de defender um Estado forte e propulsor do desenvolvimento econômico, um Estado-empreendedor.

No paradigma neoliberal, o mercado via capital externo e a maior integração às regras internacionais seriam os supostos responsáveis pelo crescimento econômico brasileiro. Desse modo, seria necessário aderir aos regimes internacionais, participar das instituições internacionais, estreitar relações com países centrais via uma dependência associada, pois em razão do sistema internacional cada vez mais interdependente o Estado-nação tem suas margens de atuação limitada, assim como o próprio modelo desenvolvimentista. Era o idealismo da globalização e da interdependência complexa preconizada por Cardoso, Lafer, Lampréia e outros.

O artigo, por fim, apresentou o denominado paradigma logístico, o qual resgatou preceitos do desenvolvimentismo econômico da CEPAL, do ISEB, da TMD e do Pensamento Independentista, entretanto os modernizaram com o Social desenvolvimentismo, a Teoria Construtivista das Relações Internacionais, a Economia do Sistema-mundo e a Teoria Realista das Relações Internacionais. O paradigma logístico saiu da universidade e conseguiu espaço na 
política externa brasileira durante o governo Lula em virtude de diversos fatores, mas particularmente pelo fracasso do paradigma neoliberal e seu sistema de ideias de que a associação utópica com o capital da burguesia de países centrais e a adesão a regimes internacionais proporcionariam desenvolvimento econômico e bem-estar social nos países periféricos.

O paradigma logístico nas Relações Internacionais não foi uma volta simples ao referencial nacional desenvolvimentismo e da PEI, mas algo novo influenciado, especialmente, pelas concepções e percepções de mundo da escola econômica do Social desenvolvimentismo e do Pensamento Independentista. No paradigma logístico, há o Estado desenvolvimentista no âmbito interno e, na dimensão internacional o metacampo a ser construído tem de ter uma atuação mais de apoiador.

* Artigo recebido em 24 de outubro de 2019, aprovado em 06 de dezembro de 2019.

\section{REFERENCIAS}

AMORIM, Celso Luiz Nunes. Política externa é uma política pública como as demais. Está sujeita à expressão das urnas [08 de abril de 2010]. Brasília. IPEA na Mídia. Entrevista concedida a Douglas Portari e João Cláudio Garcia. 2010.

AMORIM, Celso. Conceitos e estratégias da diplomacia do governo Lula. Diplomacia, Estratégia e Política, Brasília, v. 1, n. 1, out. 2004.

AMORIM, Celso. Teerã, Ramalá e Doha: Memórias da Política Externa Ativa e Altiva. São Paulo: Saraiva, 2015.

BASTOS, Pedro. P. Z. A economia política do novo-desenvolvimentismo e do social desenvolvimentismo. Revista Economia e Sociedade, v. 21, n. especial, p. 779-810, 2012.

BASTOS, Pedro. P.Z.; HIRATUKA, Celio. A política econômica externa do governo Dilma Rousseff: comércio, cooperação e dependência. Texto parta Discussão 306. Instituto de Economia Unicamp, 2017.

BIANCARELLI, André. M.; ROSSI, Pedro. L. A política macroeconômica em uma estratégia socialdesenvolvimentista. Revista Brasileira de Planejamento e Orçamento, n. 1, p. 21-38, 2014.

BIELSCHOWSKY, Ricardo. Estratégia de desenvolvimento e as três frentes de expansão no Brasil: um desenho conceitual. Economia e Sociedade, Campinas, v. 21, Número Especial, p. 729-747, dez. 2012. 
BRESSER-PEREIRA, Luiz Carlos. A Construção política do Brasil: Sociedade, economia e Estado desde a Independência. São Paulo: ed.34, 2016.

BRESSER-PEREIRA, Luiz Carlos. O empresário industrial e a revolução brasileira. Revista de Administração de Empresas, São Paulo, v.3, n.8, jul/set., p.11-27, 1963.

BRIGAGÃO, Clóvis; SILVA, Raul M. (Orgs.). História das relações internacionais do Brasil. Rio de Janeiro: Cebri, 2001.

BUENO, Clodoado. Política externa da Primeira República: os anos de apogeu, de 1902 a 1918. São Paulo: Paz e Terra, 2003.

BUENO, Clodoaldo. A República e sua política exterior: 1889 a 1902. São Paulo: USP; Brasília: Funag, 1995.

CALDAS, Ricardo W. A política externa do governo Kubitschek. Brasília: Thesaurus, 1996.

CARDOSO, Fernando Henrique; FALETTO, Enzo. Dependência e Desenvolvimento na América Latina. Rio de Janeiro: Civilização Brasileira, 2004.

CARDOSO, Fernando, Henrique. Discurso sobre a ordem mundial. Brasília: Senado Federal, 1991.

CARNEIRO, Ricardo M. Velhos e novos desenvolvimentismos. Economia e Sociedade, v. 21, n. especial, pp. 749-778, 2012.

CASTELO, Rodrigo. O Social-Liberalismo: Auge e Crise na supremacia burguesa na era neoliberal. São Paulo: Expressão Popular, 2013.

CASTRO, Marcus Faro de. De Westphalia a Seattle: a Teoria das Relações Internacionais em transição. Cadernos do REL. Brasília: UnB, 2001.

CENTRO DE PESQUISA E DOCUMENTAÇÃO DE HISTÓRIA CONTEMPORÂNEA DO BRASIL CPDOC. Fundação Getúlio Vargas, Rio de Janeiro. Arquivo Oswaldo Aranha, 1938.01 .07 cpl5.

CERVO, Amado Luiz. Inserção Internacional: formação dos conceitos brasileiros. São Paulo: Saraiva, 2008.

CERVO. Amado Luiz; BUENO, Clodoaldo. História da Política Exterior do Brasil. Brasília: UnB, 2002.

FIORI, José L. Brasil no espaço. Petrópolis: Vozes, 2001.

FONSECA, Pedro Cezar D. Desenvolvimentismo: a construção do conceito. Texto para discussão - Instituto de Pesquisa Econômica Aplicada, Brasília-Rio de Janeiro: IPEA, 2015.

FRANK, Andre G. Acumulação dependente e subdesenvolvimento. São Paulo: Editora Brasiliense, 1980.

FURTADO, Celso. O subdesenvolvimento revisitado. Economia e Sociedade, v. 1, n. 1, p. 5-19, out. 1992.

GARCIA, Marco. A. O lugar do Brasil no mundo: a política externa em um momento de transição. In: Sader, Emir. \& Garcia, Marco.A. (org.) Brasil, entre o passado e o futuro. São Paulo: Boitempo, 2010. 
GREMAUD, Amaury P.; VASCONCELLOS, Marco A.S. de; TONETO JR., Rudinei. Economia Brasileira Contemporânea. São Paulo: Atlas, 2007.

GUIMARÃES, Samuel. P. Desafios brasileiros na era dos gigantes. Rio de Janeiro: Contraponto, 2006.

GUIMARÃES, Samuel. P. Uma política externa para enfrentar as vulnerabilidades e disparidades. In: JAKOBSEN, Kjeld (org.) A nova política externa. São Paulo: Perseu Abramo, 2010.

JAGUARIBE, Hélio. Desenvolvimento Econômico e Desenvolvimento Político. Rio de Janeiro: Paz e Terra, 1969.

JOHNSON, Chalmers. MITI and the Japanese Miracle. Stanford: Stanford University Press, 1982.

KEOHANE, Robert. O.; NYE, Joseph. S. Power and Interdependence. New York: Longman, 2012.

KUHN, S. Thomas. A estrutura das revoluções científicas. São Paulo: Perspectiva, 1998.

LAMPRÉIA, Luiz. F. A política externa do governo FHC: continuidade e renovação. Revista Brasileira de Política Internacional, v. 42, n. 2, p. p. 5-17,1998.

LIST, Friedrich. Sistema Nacional de Economia Política. São Paulo: Abril Cultural, 1983. (Coleção Os Economistas).

MARINI, Ruy. M. Dialética da dependência. Petrópolis: Vozes, 2000.

MARTINS, Carlos. E. Globalização, Dependência e Neoliberalismo na América Latina. Rio de Janeiro: Boitempo, 2011.

MERCADANTE, Aloizio. Brasil: A Reconstrução Retomada, São Paulo: Terceiro Nome, 2010.

MERLE, Marcel. Forces et en jeux dans les relations internationals. Paris: Economica, 1985.

MORAES, Isaías A.; AGUIAR, Mônica H.P.; TAUIL, Carlos E. Relações Brasil-China: uma parceria para desenvolvimento ou uma relação de codependência? Revista de Desenvolvimento Econômico, ano XX, v.2, n40, Salvador, p.402-432, 2018.

MOURA, Gerson. Autonomia na dependência: a política externa brasileira de 1930 a 1942. Rio de Janeiro: Nova Fronteira, 1980.

PADULA, Raphael; FIORI, José L. Geopolítica e Desenvolvimento em Petty, Hamilton e List. Revista de Economia Política, São Paulo, vol. 39, nº 2 (155), p. 236-252, 2019.

PETTY, William. Tratado dos Impostos e Contribuições. São Paulo: Abril Cultural, 1983 (Coleção Os Economistas).

PETTY, William. Aritmética política. São Paulo: Abril Cultural, 1983. (Coleção Os Economistas).

PREBISCH, Raul. O falso dilema entre desenvolvimento econômico e estabilidade monetária. São Paulo: Ordem dos Economista, 1961.

RICUPERO, Rubens. A diplomacia na construção do Brasil: 1750 - 2016. Rio de Janeiro: Versal, 2017. 
SILVA, Luís Inácio Lula da. Discurso de posse do Presidente Lula [01 de jan. 2003]. Biblioteca Presidência, Brasília 2003.

TRASPADINI, Roberta. A Teoria da (Inter) Dependência de Fernando Henrique Cardoso. São Paulo: Outras Expressões, 2014.

VIGEVANI, Tullo; OLIVEIRA, Marcelo F. de; CINTRA, Rodrigo. Política externa no período FHC: a busca de autonomia pela integração. Tempo soc., São Paulo, v. 15, n. 2, p. 31-61, Nov. 2003.

VIGEVANI, Tullo; CEPALUNI, Gabriel. A política externa de Lula da Silva: a estratégia da automonia pela diversificação. Contexto internacional, Rio Janeiro, v. 29, n. 2, p. 273-335, 2007. 